\title{
Successful management of spontaneous bone regeneration after jaws cystectomy using PRGF approach; case series
}

\author{
Cristian Adrian Ratiu ${ }^{1)}$, Ioana Adela RatiuU2), Simona Cavalu3), Adina Bianca BoşCa ${ }^{4}$, \\ GABRIELA CIAVOI ${ }^{1)}$ \\ 1) Department of Dental Medicine, Faculty of Medicine and Pharmacy, University of Oradea, Romania \\ 2) Department of Medical Disciplines, Faculty of Medicine and Pharmacy, University of Oradea, Romania \\ 3) Department of Preclinical Disciplines, Faculty of Medicine and Pharmacy, University of Oradea, Romania \\ 4) Discipline of Histology, Department of Morphological Sciences, Faculty of Medicine, \\ Iuliu Hatieganu University of Medicine and Pharmacy, Cluj-Napoca, Romania
}

\begin{abstract}
In the jaws, the healing process of bone defects occurs differently compared with other anatomical sites where healing is done by the formation of scar tissue. This is due to physiological bone remodeling and continuous bone resorption and apposition. In the case of large cysts, there is an increased risk of postoperative infection due to the retraction of the blood clot on the bony walls. The use of plasma rich in growth factors (PRGF), with or without autologous bone addition, for filling the cystic cavities is beneficial not only for its antimicrobial effect, but also due to simultaneously release of growth factors from platelet alpha granules and adhesive proteins. The aim of our work was to emphasize the spontaneous bone healing of the maxilla and mandible after the enucleation of large and medium-sized cysts in asymptomatic patients of different age. The outcome of three patients who underwent surgery for removal of radicular cysts is presented. Imagistic [cone-beam computed tomography (CBCT)] and histological examination was performed aiming to evaluate the quality of new bone at the site of the bone defect, after different time intervals. By using PRGF approach, the healing of mandibular bone occurred 18 months after cystectomy in a smoker patient, 54-year-old, while the healing of maxillary bone using autologous bone mixed with PRGF occurred after six months in a 63-year-old patient. In a young patient (14 years old), the regeneration period was six months, using PRGF and a fibrin cloth for filling the defect.
\end{abstract}

Keywords: bone regeneration, odontogenic cyst, enucleation, PRGF.

\section{Introduction}

Odontogenic cysts are common lesions of the jaws and the therapeutic approach is the complete enucleation, which results in a bone defect. The formation of a blood clot within the bone defect, followed by the correct suture of the wound and the spontaneous healing of the bone tissue is widely accepted [1-4]. Healing of bone defects depends on their size and shape, the anatomical location, the age of the patient [3] and other factors such as the blood supply and the presence of a compact bone support to promote the formation of new bone [2]. The transformation of the blood clot into granulation tissue and then into bone tissue is stimulated by cytokines, chemokines, growth factors and stem cells [5-8]. It is well known that platelets play a crucial role in hemostasis and healing processes. Several studies reported that, due to concentrated platelets, the use of autologous plasma rich in growth factors (PRGF) promotes the regeneration of bone and soft tissues, thus improving the therapeutic outcome $[9,10]$. The activated platelets release a wide variety of biologically active molecules, such as: vascular endothelial growth factor (VEGF), and platelet-derived growth factor (PDGR), transforming growth factor-beta 1 (TGF- $\beta 1$ ), and insulinlike growth factor-1 (IGF-1), which stimulate the healing process. The amount of growth factors released into the healing wound depends on the concentration of platelets [11]. The most prominent immunomodulatory mediators include cytokines such as: interleukins (IL-1 $\beta$, IL-8) and monocyte chemotactic proteins (MCP-1, MCP-2, and $\mathrm{MCP}-3$ ) that play essential roles in tissue healing. A list of the growth factors and their functions is well documented and reported by Rodriguez et al. [12].

In the case of large cysts, there is an increased risk of postoperative infection due to the retraction of the blood clot on the bony walls; for this reason, it is recommended to fill the bone defect [2]. Over time, various biomaterials have been used to fill bone defects: autologous bone [1, 13], allografts $[14,15]$, xenografts $[16,17]$ or alloplasts $[18,19]$. Moreover, bone addition materials were combined with platelet-rich plasma (PRP) in order to accelerate the integration at site of the bone defect $[20,21]$, and are used as substitutes for autografts, thus avoiding the disadvantages associated with autologous bone graft harvesting. Since the use of autografts is the most common procedure for surgical reconstruction of bone defects, it was demonstrated the short- and long-term success of autologous bone in combination with autologous platelet gels in oral and maxillofacial bone regenerations (compared to autograft alone) [12-14]. However, the management of large jaw cysts is still a challenge, even if the principle of early marsupialization, followed by enucleation after initial

This is an open-access article distributed under the terms of a Creative Commons Attribution-NonCommercial-ShareAlike 4.0 International Public License, which permits unrestricted use, adaptation, distribution and reproduction in any medium, non-commercially, provided the new creations are licensed under identical terms as the original work and the original work is properly cited. 
bone healing, was first proposed by Killey et al. [22] in 1977. It varies from aggressive lines to minimal invasive procedure, attempting to minimize the risk of recurrence. Nowadays, it is widely accepted that marsupialization is indicated in the case of large cysts, either in elderly, debilitated patients, or in young patients with developing tooth gums.

\section{Aim}

In this context, the aim of our study was to assess the spontaneous healing of the maxilla and mandible after the enucleation of large and medium-sized cysts in asymptomatic patients of different age. PRGF and fibrin clot were employed to fill the bone defects, instead of the blood clot. Both classical radiology and cone-beam computed tomography (CBCT) investigations were performed in order to evaluate the quality of regenerated bone after surgery, while histological examination was performed in order to emphasize the microscopically details of newly formed bone.

\section{Patients, Materials and Methods}

The outcome of three patients who underwent surgery for removal of radicular cysts is presented: two patients exhibited cysts located in the mandible and one patient exhibited a cyst located in the maxilla. The study was performed in agreement with the ethical standards of the Helsinki Declaration and approved by the Ethics Committee of University of Oradea (Romania), Faculty of Medicine and Pharmacy (Approval No. 2/26.05.2020). All patients signed an informed consent agreement for the surgical protocol. In all three cases, the symptomatology was absent (the Dupuytren's sign was negative); the diagnosis of radicular cyst was based on clinical and radiological examination. In all surgical interventions, $40-80 \mathrm{~mL}$ of blood were collected in sterile tubes with sodium citrate; the tubes were centrifuged for eight minutes at $560 \mathrm{G}$ for separating the plasma from erythrocytes and leukocytes. By pipetting, the plasma was separated into two fractions: fraction 2, from which PRGF was obtained, and fraction 1, from which the fibrin clot was obtained. Activation of both fractions was performed with calcium chloride $\left(\mathrm{CaCl}_{2}\right)$ according to Anitua (et al.) protocol [23-25]. After surgery, the patients received the following treatment: Amoxicillin (Antibiotice Iaşi ${ }^{\circledR}$ ) 2 g, one hour preoperatively and $500 \mathrm{mg}$ every eight hours for five days and Ketorol (Dr. Reddy's $^{\circledR}$ ) $10 \mathrm{mg} \times 3 /$ day, postoperatively. The nonabsorbable sutures were removed 7-10 days postoperatively. Patients used $0.12 \%$ Chlorhexidine, three times daily, as a local antimicrobial for three days preoperatively, with an interruption on the day of the intervention, and for two weeks postoperatively.

The bone healing process was monitored by radiological examination, after different time intervals, using the instrument RayScan $\alpha$-SM3D (Samsung, Hwaseong, Korea). The details and the quality of the new bone formed at the site of the bone defect were evidenced by histological examination. The tissue specimens were fixed in $10 \%$ neutral buffered formalin solution, decalcified, embedded into paraffin, sectioned, and stained with Goldner's trichrome technique. The microscopic examination was performed with an Olympus BX41 microscope (Tokyo, Japan).

\section{口 Results \\ Clinical case presentations and surgical procedure}

\section{Clinical Case No. 1}

A patient aged 54-year-old, smoker, presented to the dental clinic for the extraction of residual roots of teeth 3.6 and 3.7 (Figure 1A). On the panoramic radiograph (Figure 1B), a homogeneous, well-defined radiolucency was observed, which extended vertically $(2.8 \mathrm{~mm})$ from the bone crest to the base of the mandible and horizontally $(3.7 \mathrm{~mm})$ from the ramus to the mental foramen. The inferior alveolar artery-vein-nerve complex was embedded in the mass of the cyst, but no sensitivity disorders in the lower lip (negative Vincent d'Alger sign) were reported by the patient. Additionally, in the place corresponding to tooth 3.5, a homogeneous, well-defined, round radiolucency with the diameter of approximately $0.5 \mathrm{~mm}$ was observed and diagnosed as a residual cyst. An incision was made from the retromolar space to the distal surface of tooth 3.4 , with an oblique incision towards the apex of tooth 3.4; after the detachment of the mucoperiosteal flap, the buccal surface of the mandible body was exposed, and it was intact. Using a Lindemann drill, a bony flap was removed (Figure 1C) and deposited in fraction 2 (Figure 1D). Both cysts were curetted, preserving the integrity of the inferior alveolar nerve (Figure 1E). The bone flap was fragmented using a bone drill and then maintained in fraction 2, which was activated with $10 \% \mathrm{CaCl}_{2}$ (Figure $1 \mathrm{~F}$ ). Then, the activated fraction 2 was introduced at the base of the bone defect (Figure 1G) and covered by the fraction 1 (the fibrin clot) (Figure 1H). The surgical wound was sutured with non-absorbable suture threads, which were removed after 10 days. The healing process was appropriate, without any dehiscences (Figure 1, I and J). Panoramic radiograph (Figure 1K) and CBCT (Figure 1L) performed after 18 months showed bone formation inside the bone defect. The patient chose the insertion of implants at the level of the edentulous area. One implant (diameter $3.5 \mathrm{~mm}$, length $15 \mathrm{~mm}, \mathrm{TBR}^{\circledR}$ ) was inserted in the place of tooth 3.5 and one implant (diameter $5 \mathrm{~mm}$, length $13 \mathrm{~mm}, \mathrm{TBR}^{\circledR}$ ) in the place of tooth 3.6. Simultaneously with the insertion of the implant, a bone core was harvested with a trephine drill from the alveolar crest corresponding to tooth 3.7 (Figure 1M). The panoramic radiograph performed after the insertion of the implants showed an appropriate osseointegration (Figure 1N).

The histological examination revealed, at the site of the bone defect, the new bone formation consisting of both mature lamellar bone and primary, woven bone (Figure 2A). The compact bone was located at the surface and formed a thick cortical plate. It included osteons, with Haversian canals and concentric bone lamellae, containing formative osteocytes resting in lacunae and surrounded by osteoid (Figure 2B). The spongy bone was present in the profound area and consisted of bone lamellae organized in trabeculae with embedded formative osteocytes (Figure 2C). The primary, woven bone was present both in the superficial and profound areas, associated with the compact bone and the spongy bone, respectively. It was characterized by a disorganized, nonlamellar structure, numerous formative osteocytes and abundant hypomineralized bone matrix (Figure 2, D and E). 

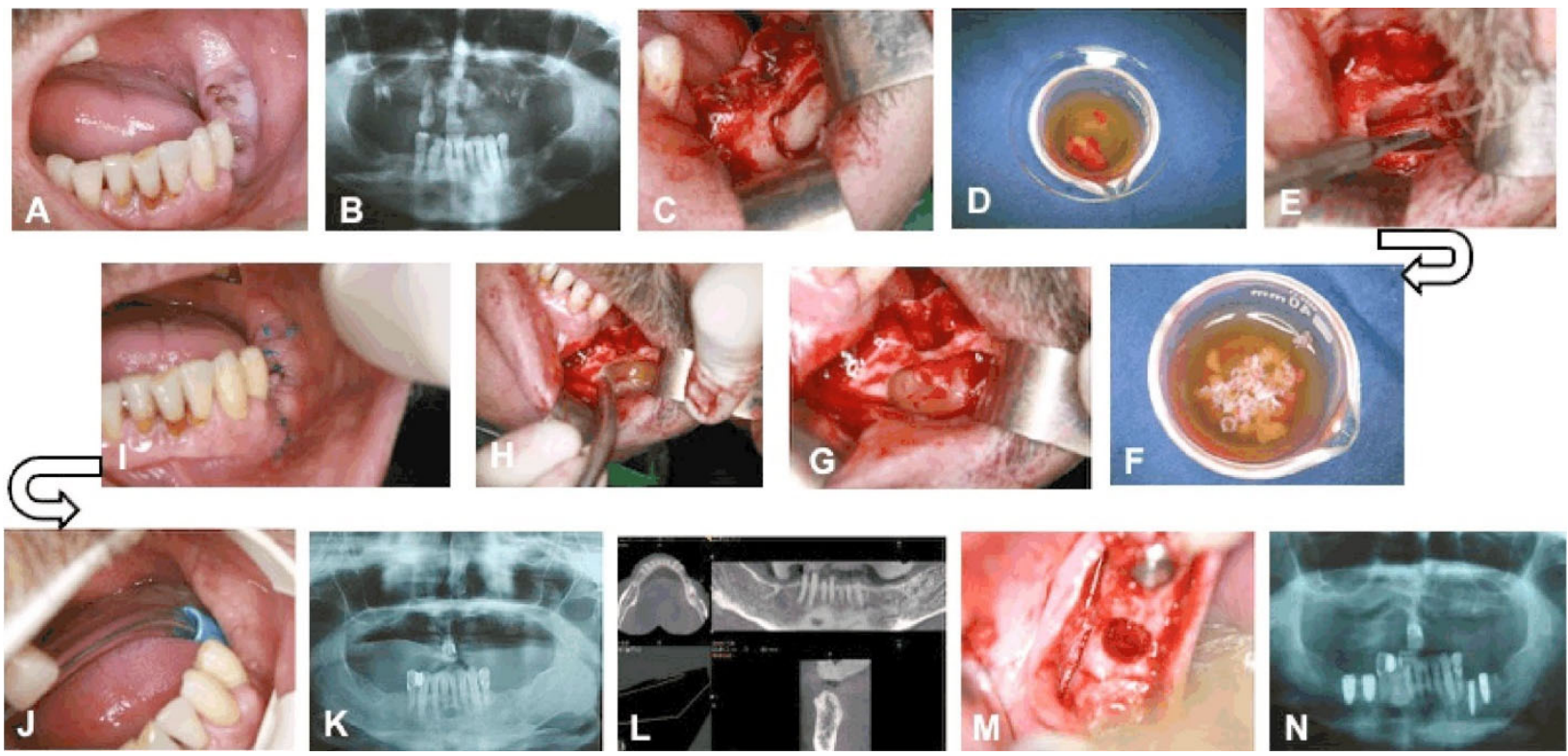

Figure 1 - Clinical Case No. 1. Surgical procedure and radiological examination: (A) Residual roots of teeth 3.5 and 3.7; (B) Radiolucency localized on the left side, in the body of the mandible, associated with the residual roots of tooth 3.7; (C) Removal of the bone flap at the site of teeth 3.6 and 3.7; (D) The bone flap immersed into fraction 2; (E) Preservation of the integrity of the inferior alveolar nerve during cyst enucleation; $(F)$ The fragmented bone flap maintained in fraction 2 activated with $\mathrm{CaCl}_{2}$; (G) Fraction 2 and the autologous bone applied at the base of the bone defect; (H) Filling the bone defect with fibrin clot; (I) Healing 10 days after the intervention; (J) Healing 18 months after the intervention; (K) The radiological examination 18 months after the intervention; (L) CBCT showing the bone formation at the site of the bone defect; (M) Harvesting of the bone tissue with the trepanning drill for inserting the implants; (N) The radiological examination after inserting the implants, showing the site of bone harvesting from the former bone defect. CBCT: Cone-bean computed tomography.

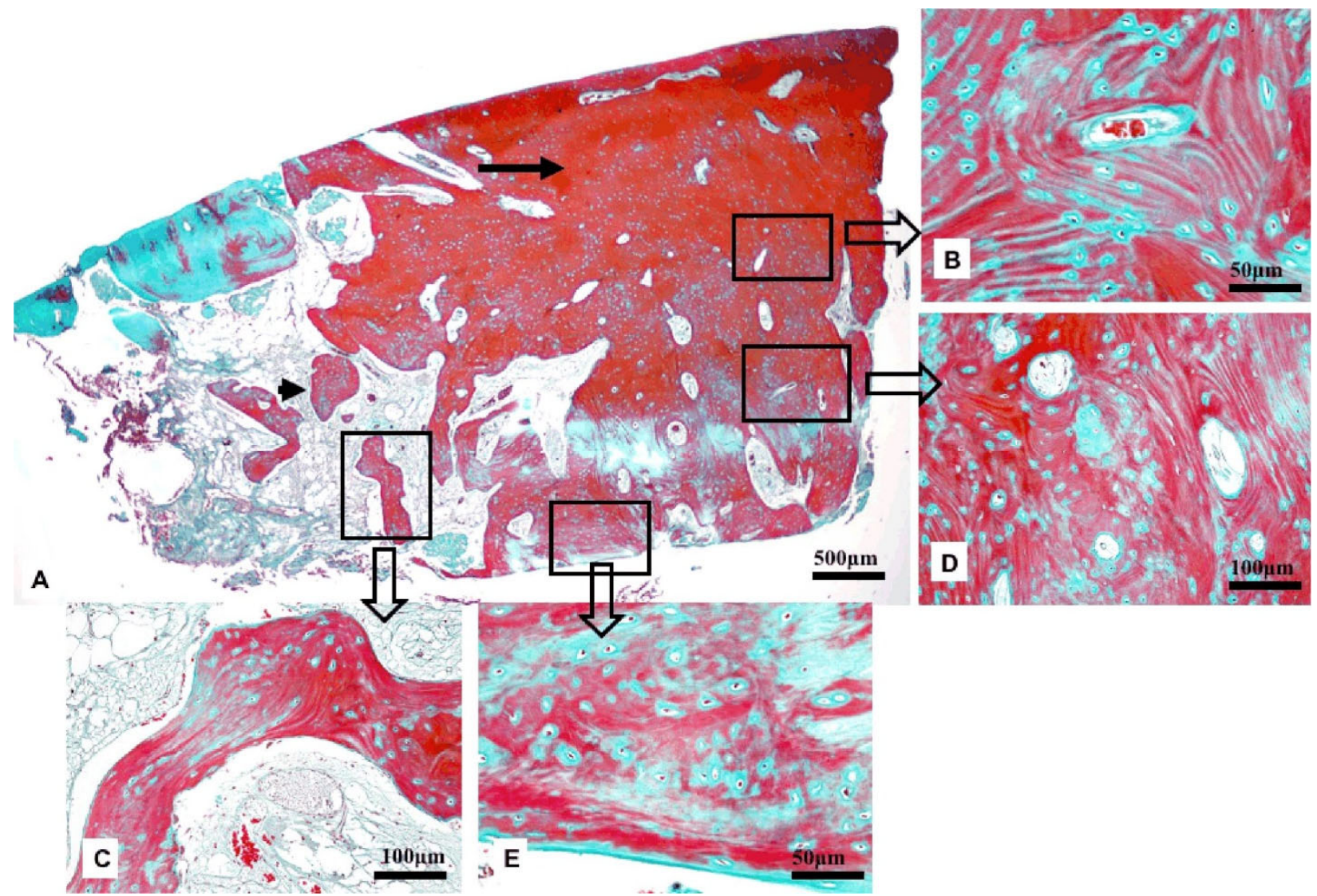

Figure 2 - Photomicrograph of the new bone formed at the site of the bone defect in Case No. 1: (A) Thick compact bone at the surface (arrow) and spongy bone in the profound area (arrowhead); (B) Lamellar compact bone with osteons centered by Haversian canals and concentric lamellae; (C) Spongy lamellar bone with trabeculae delimiting areoles; (D) Primary, woven bone in the superficial area; (E) Primary, woven bone in the profound area. Goldner's trichrome staining. 


\section{Clinical Case No. 2}

A patient aged 63-year-old, non-smoker, presented to the dental clinic for an implant-prosthetic treatment. Panoramic radiograph showed a homogeneous, well delimited oval-shaped radiolucency, measuring approximately $15 / 10 \mathrm{~mm}$ in size, located at the level of teeth 2.1, 2.2 and 2.3 (Figure 3A). The clinical examination revealed the preparation of teeth $2.1,2.2,2.3$ and the integrity of the mucosa on the vestibular surface of the maxilla (Figure 3B). The root canal treatment for tooth 2.3 was performed under a microscope $\left(\right.$ Zeiss $\left.^{\circledR}\right)$, followed by surgery for the insertion of implants in the distal part of the maxilla and for the cyst enucleation. After the incision and detachment of the mucoperiosteum, the integrity of the vestibular face was observed (Figure 3C) and a bone window was cut at the level of teeth 2.1 and 2.2 using a Lindemann drill (Figure 3, D and E). Thus, the radicular cyst was exposed and enucleated. Both the bone flap and the bone obtained during the insertion of the implants in the distal area were deposited in fraction 2 (Figure 3F). Similar to the previous case, the insertion of the implants was done using a drill without cooling. Then, the bone flap previously fragmented and the fraction 2 activated with $10 \% \mathrm{CaCl}_{2}$ were applied in the bone defect resulted after the enucleation of the cyst and the extraction of teeth 2.1 and 2.2. The defect could not be completely filled with the bone harvested from the drilling cutter; for the complete filling of the bone defect, the fraction 1, representing the fibrin clot, was added on top of the other materials (Figure $3 \mathrm{G}$ ). After six months, the panoramic radiograph showed the formation of bone tissue at the site of the bone defect (Figure 3H). The detachment of the muco-periosteal flap highlighted the formation of the vestibular cortical bone, but with a depression on the bone surface at this level (Figure 3I). The implants were inserted using a trephine drill that allowed the harvesting of a bone carrot (Figure 3J), which was histologically analyzed. The macroscopic aspect and the tactile sensation when inserting the implants suggested the bone regeneration. The panoramic radiograph showed the osseointegration of the implant at the site of the former bone defect (Figure 3K).

The histological findings indicated features consistent with the tissue healing in the maxillary bone defect (Figure 4A). The compact bone at the surface was thin (Figure 4B), whereas the spongy bone was abundant in the profound area (Figure 4C). The structure of the compact bone was characterized by a concentric lamellar architecture, and the primary woven bone was absent in the superficial zone (Figure 4D). The bone trabeculae were thick, lined by active osteocytes and contained formative osteocytes surrounded by a thin layer of osteoid (Figure 4C). The primary, woven bone was reduced in amount and present only on the deeper zones, associated with the trabeculae of the spongy bone (Figure 4E).

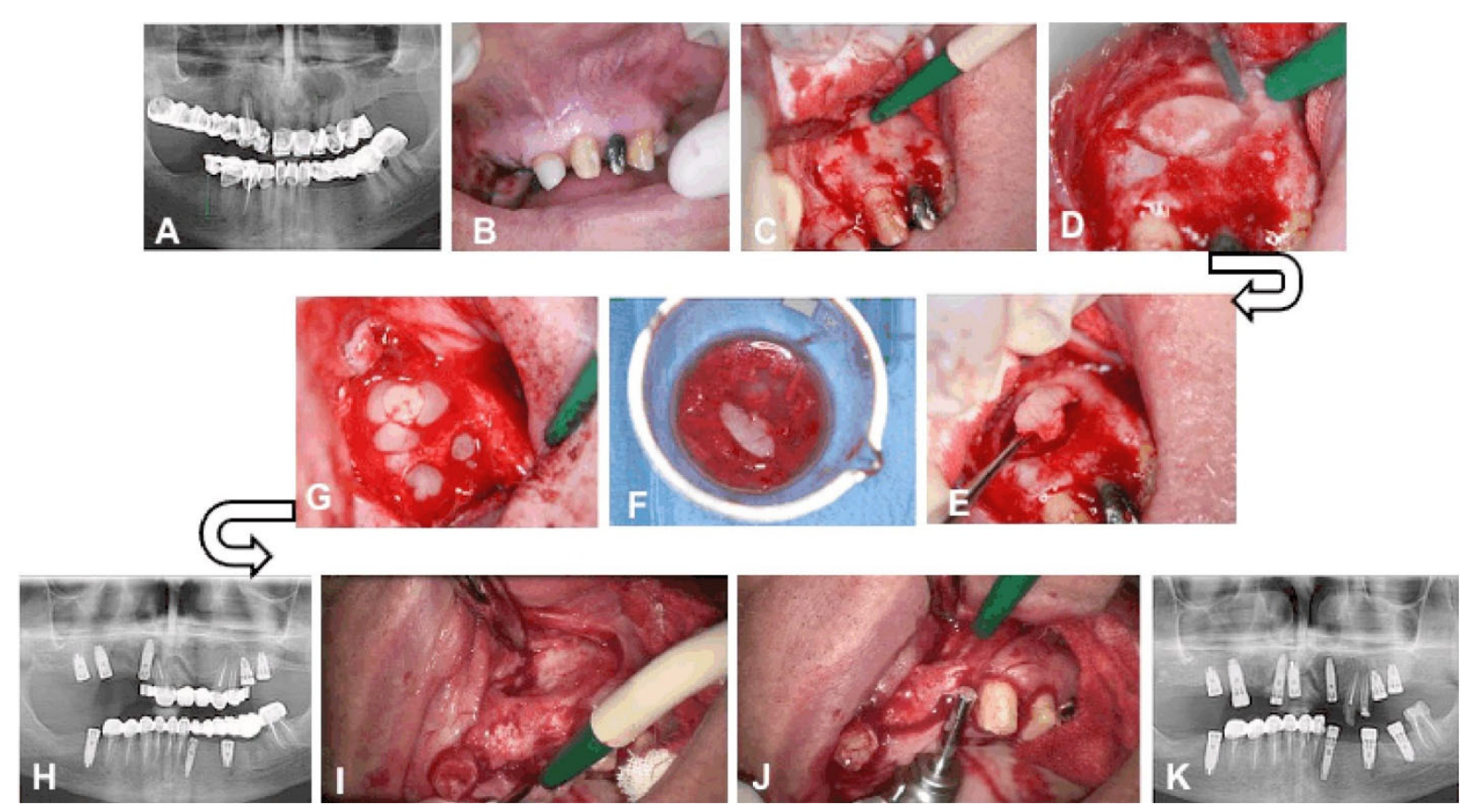

Figure 3 - Clinical Case No. 2. Surgical procedure and radiological examination: (A) Radicular cyst associated with teeth 2.1, 2.2 and 2.3; (B) The integrity of the vestibular alveolar mucosa corresponding to teeth 2.1., 2.2 and 2.3; (C) The integrity of the vestibular cortical bone; (D) The bone flap cut with a Lindemann drill; (E) Removal of the bone flap; (F) The bone flap and the bone tissue obtained by inserting the implants immersed in fraction 2; (G) Filling the bone defect with autologous bone mixed with PRGF and fibrin clot; (H) Panoramic radiograph showing the new bone formation after six month; (I) The aspect of the vestibular cortical plate at the site of the former bone defect; (J) Harvesting of bone tissue with the trepanning drill during inserting the implants; (K) Panoramic radiograph showing the osseointegration of the implant in the bone at the site of the former bone defect. PRGF: Plasma rich in growth factors. 


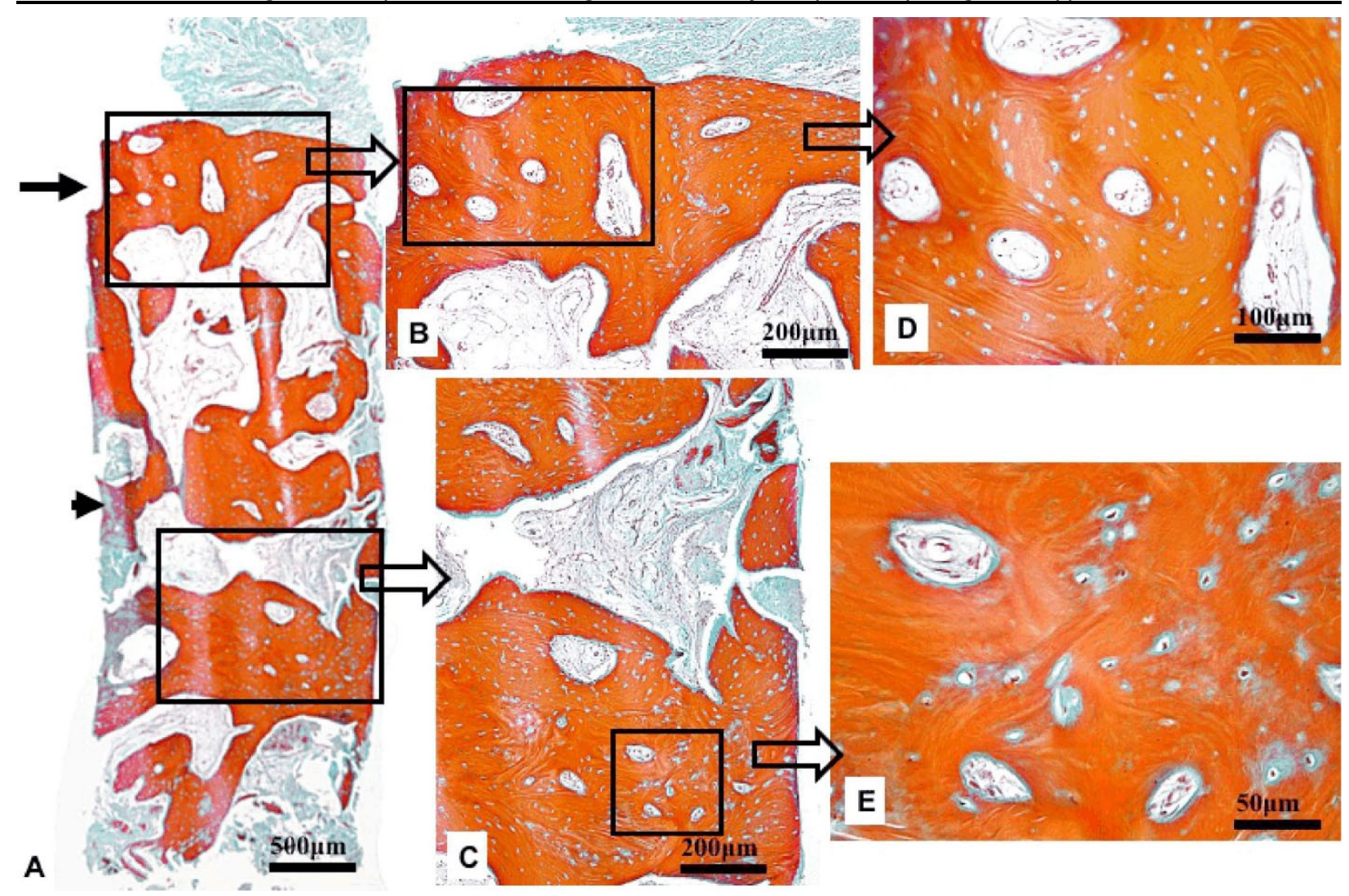

Figure 4 - Photomicrograph of the bone healing in Case No. 2: (A) Thin cortical compact bone at the surface (arrow) and abundant spongy bone in the profound area (arrowhead); (B) Compact bone with lamellar architecture; (C) Spongy lamellar bone with thick trabeculae delimiting areoles; (D) Osteons including Haversian canals surrounded by lamellae; (E) Low amounts of primary, woven bone associated with the bone trabeculae. Goldner's trichrome staining.

\section{Clinical Case No. 3}

A 14-year-old patient presented to the private dental office for a follow-up after a root canal treatment for tooth 3.6. The retroalveolar radiograph showed a homogeneous, well-delimited radiolucency in the proximity of the apexes of tooth 3.6. The radiolucency extended apically up to the inferior alveolar nerve, coronary between the mesial and distal roots (with a width of $10 \mathrm{~mm}$ ), distally up to tooth 3.7 but without affecting this tooth, and mesially up to tooth 3.5 without reaching the apex of this tooth (length $22 \mathrm{~mm}$ ) (Figure 5A). In order to extract tooth 3.6, an incision was made at level of teeth 3.7 and 3.6, which extended apically towards tooth 3.4. After the flap was detached, the integrity of the bone was observed; a trapezoidal bony flap was cut with piezosurgery (Vario Surg NSK $^{\circledR}$ ) and removed, thereby the radicular cyst was exposed. Tooth 3.6 was extracted and the cyst was removed. The bony flap was repositioned approximately in the initial location, where the primary stability was enabled due to its trapezoidal shape. The communication of the bone defect with the oral cavity on the vestibular surface was made through a bone window reduced by $50 \%$ by placing the bone flap in position (Figure $5 \mathrm{~B}$ ). The bone defect was filled with PRGF and fibrin clot (Figure 5C). The patient returned after six months, when the clinical (Figure 5D) and the radiological aspects (Figure 5E) revealed the healing of the postoperative wound and the bone regeneration. The patient agreed with an orthodontic treatment aiming the mesialization of teeth 3.7 and 3.8 for the closure of the edentulous space.
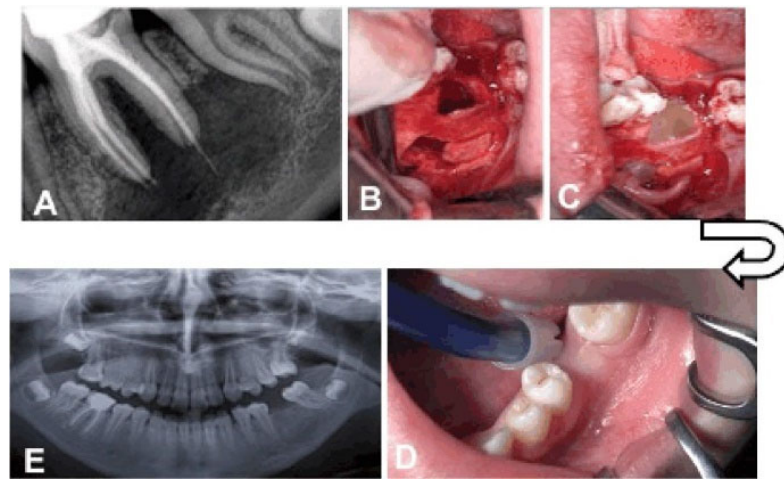

Figure 5 - Clinical Case No. 3. Surgical procedure and radiological examination: (A) Retro-alveolar radiograph showing the radicular cyst associated with tooth 3.6; (B) Repositioning of the cortical bone wall at the site of the bone defect; (C) Filling of the bone defect with PRGF, fractions 1 and 2; (D) Clinical examination six months after the intervention; (E) Radiological examination six months after the intervention. PRGF: Plasma rich in growth factors.

\section{ㅁ Discussions}

In all three cases, the aim was to create access, as small as possible, but enough to get the necessary area for the complete removal of the cysts. A smaller bone defect after cyst removal provides adequate support for soft tissues and promotes bone regeneration [1]. Moreover, in order to prevent bone necrosis, irrigation with sterile saline was performed during drilling. In Cases No. 2 
and No. 3 , the cysts were enucleated in one piece, while in Case No. 1, increased attention was focused on maintaining the integrity of the inferior alveolar nerve and thereby, the enucleation of the cyst in one single piece was not successful. Paresthesia of the inferior alveolar nerve remitted six months after the operation. The cystic cavities have been carefully cured so that no fragments remained, avoiding possible recurrence. In the first two cases, the histological and radiological examinations confirmed the new bone tissue formation at the site of the bone defect, while in Case No. 3, the clinical examination and the panoramic radiograph was enough to confirm the bone regeneration at the site of the bone defect. All three cases had in common the fact that the enucleation of the cyst was done simultaneously with the tooth extraction and consequently, resulted in a bone defect with two missing bone walls. It is also very important to mention that in all three cases the cyst did not erode neither the vestibular, nor the oral cortical bone, so the periosteum was intact. On the other hand, there are some particular features of each case. In Case No. 1, the bone defect was filled with PRGF, fibrin clot and a small amount of bone resulting from the fragmentation of the bone flap. In Case No. 2, the bone defect was filled with a large amount of bone resulting from the drilling, without cooling, performed for the insertion of the implants in the distal area. In Case No. 3, the bone defect was filled only with PRGF; by the reposition of the bone flap, one of the walls of the bone defect was almost entirely restored, thereby the bone defect had with only one wall missing. The histological findings in first two cases were consistent with the clinical and radiological evidences, showing an appropriate healing at the site of the bone defects. However, in Case No. 2, a more advanced regeneration stage was noticed, characterized by an increased volume of mature, lamellar bone, and a lower amount of woven bone, compared with the first case. Healing of bone defects in the jaws occurs differently compared with other anatomical sites where healing is done by the formation of scar tissue. This is due to physiological bone remodeling and continuous bone resorption and apposition. The evolution of bone defects resulting from the removal of small cysts is normally towards spontaneous bone regeneration; controversies arise in large cysts [1]. At the level of the mandible, spontaneous healing of bone defects up to $5 \mathrm{~mm}$ was reported; bone defects of 2-3 $\mathrm{mm}$ in size have better spontaneous bone healing after one year compared with larger ones [3]. In the mandible, the bone defects localized at the level of the mandibular body have a lower potential for spontaneous bone healing compared to those in the symphysis or in the angle of the mandible; this is due to poor vascularity. On the other hand, it seems that the shape of the defect is more important than its size; the elliptical shape has a much better healing than the round shape. The higher the difference between the maximum and minimum size of the defect, the better the healing. Moreover, defects with a single bone wall heal better than those with two missing walls and, of course, healing is better in young people, up to the age of 30 to 33 years old [3]. Surgical technique is of particular importance in the spontaneous healing of bone defects; by creating an access smaller by $10 \mathrm{~mm}$ than the size of the cyst, a reduced size of the missing bone wall will promote the spontaneous healing. Even if the remaining bone walls are thin, they will promote osteogenesis [1, 3]; at the same time, they will enable the retention of the blood clot inside the bone defect and an adequate support for the bone or the mucoperiosteal flap [1]. The use of resorbable or non-resorbable membranes does not ensure better healing if the periosteum is intact. This is why the surgical technique must ensure the integrity of the periosteum; otherwise, the defect will be partially filled with connective tissue [1]. In the first two cases, a Lindemann drill was used to cut the bone flap, which was then fragmented, mixed with PRGF, and inserted into the bone defect. In the third case, the bone flap was cut with piezosurgery and part of it could be repositioned so as to partially close the bone defect, thus offering a greater support for the soft tissues. At the same time, the opening of the cavity was reduced, limiting the risk of detachment of the clot from the bone walls. The use of piezosurgery allows a precise cut [26] and smaller bone flap dimensions; in this way, the re-positioning and stabilization of the bone window is much easier. Moreover, the use of piezosurgery has the following advantages: selective cutting action, intraoperative surgical control, blood-free surgical site, favorable osseous response, reduced operation stress [27-31]. Selective tissue cutting by using piezosurgery allows the preservation of the integrity of the cystic membrane and therefore enables the complete removal of the cyst; as a result, the risk of recurrence decreases. In order to cut the bone window, a diamond disk can be used, such as MicroSaw (Frios Dentsply Sirona $\left.{ }^{\circledR}\right)$, which allowed a very thin cut $[32$, 33]; by this way, the speed of osteotomy is increased. Compared to the use of piezosurgery, the risk of sectioning the cystic membrane is higher. The shape of the bone flap after osteotomy allowed the stability of the bone flap after repositioning. The reason of filling the cystic cavities with bone addition material derives from the risk of infection in the case of larger cysts, which is caused by the retraction of the clot from the bone walls [2]. Bone addition materials reduce the risk of infection, accelerate bone regeneration, prevent invasion of connective tissue into the bone defect, and improve bone density [2]. Autologous bone is still the "gold standard" as bone addition material. Experimental studies on minipigs in which $10 / 5 \mathrm{~mm}$ bone defects were performed in the mandible revealed that bone defects filled with autologous bone had the highest regeneration rate in the initial healing phase, compared to blood-filled bone defects [2, $3]$. According to these studies, after 12 months, the bone density and quality of the newly formed bone was the same. Consequently, considering the need to perform an intervention under general anesthesia to harvest the spongy bone from the iliac crest, it is obvious that the decision must be well analyzed. For bone defects in which more than one bone wall is missing, or in which the periosteum is affected, the autologous bone prevents the collapse of the soft tissue, preserves the bone volume and it is a source of osteogenic cells and growth factors [2]. Considering that for long term, the filling of bone defects with autologous bone harvested from the iliac crest does not offer major advantages, it can be concluded that the spontaneous healing of bone defects after cystectomy is a viable method of treatment with good results and low costs. In this context, the use of platelet 
concentrates is an optimal approach for the treatment of bone defects [34-36]. On the other hand, filling the bone defect with autologous bone alone or in combination with alloplastic biomaterial presents some drawbacks, such as increased costs, autologous bone harvesting and related infection propensity or other complications, such as resorption [1]. At the present, there are insufficient data to attest a substantial reduction in the risk of infection, consecutive to cyst enucleation, by using autologous, allogeneic bone or autologous bone in filling the bone defect [2]. PRGF stimulates key mechanisms involved in the healing processes, such as: proliferation, migration, chemotaxis, and release of molecules with angiogenic and anti-inflammatory effect and synthesis of extracellular matrix components [37]. PRGF has an antimicrobial effect on several bacterial species including Enterococcus faecalis, Candida albicans, and Streptococcus agalactiae oralis [38]. Since infection is one of the complications of cystectomies, the use of PRGF for filling the cystic cavities is beneficial, due to its antimicrobial effect. By adding $\mathrm{CaCl}_{2}$, the plasma is activated, and within few minutes, it turns from a liquid form into a clot. Simultaneously with the release of growth factors from platelet alpha granules, adhesive proteins such as fibronectin, vitronectin, von Willebrand thrombospondin factor and laminin are released [37, 38]. Increased adhesion of cyst bone walls is of major importance, given that the cause of complications in large cysts is the detachment of the clot from the bone walls, leading to infection. It was demonstrated that filling large cystic cavities with PRGF can be the elective method in their treatment due to the multiple properties of PRGF: stimulates bone healing, decreases inflammation, antibacterial effect, increases adhesion to the bone wall, reduces postoperative pain. The regeneration of small to medium bone defects may occur within 12 months, in the case of cyst enucleation; in the case of large defects, the regeneration time may extend to 24 months [1-3]. In the first case presented in this work, the healing of the bone occurred 18 months after the intervention; considering that the patient was 54-year-old (and this age is associated with low osteogenic activity) and was a smoker, the healing could be considered very well. In the second case, the bone tissue recovered from the drill and mixed with PRGF was used for filling the bone defect; the healing after six months was good, considering the patient's age, the shape of the bone defect and the fact that two bone walls were missing. It should be noted that the healing resulted in a depression of the vestibular cortical plate at the site of the access into the cystic cavity. Of course, in a young patient, the healing six months after the cystectomy (third case) was also very good, by using PRGF and the surgical technique, even if the bone defect had two missing walls.

\section{ㅁ Conclusions}

Spontaneous healing of the bone after cystectomy and filling the cystic cavity with PRGF was assessed in three different cases in which the enucleation of the cyst was done simultaneously with the tooth extraction. As a result, a bone defect with two missing bone walls was created. A slower healing of the mandibular bone defect was noticed in a smoking patient, 54-year-old. After 18 months, the bone density was favorable for implant insertion and the histological examination showed an appropriate bone healing, with a thick lamellar compact bone at the surface and lamellar spongy bone in the profound area. The woven bone was present both in association with the compact bone and the spongy bone. By comparison, the healing of the maxillary bone defect filled with autologous bone mixed with PRGF, resulted in a depression of the vestibular cortical plate. After six months, the bone density was appropriate, as the histological examination evidenced the newly formed bone, characterized by a thin cortical plate and a thick trabeculae with low amounts of primary, woven bone. A good healing process was noticed, considering the age of the patient (63-year-old). In a very young patient (14-year-old), six months after the surgery, the radiological aspect of the new bone formed at the site of the defect was almost identical to that of the surrounding bone.

\section{Conflicts of interests}

The authors declare no conflict of interest.

\section{References}

[1] Chiapasco M, Rossi A, Motta JJ, Crescentini M. Spontaneous bone regeneration after enucleation of large mandibular cysts: a radiographic computed analysis of 27 consecutive cases. J Oral Maxillofac Surg, 2000, 58(9):942-948; discussion 949. https://doi.org/10.1053/joms.2000.8732 PMID: 10981973

[2] Ettl T, Gosau M, Sader R, Reichert TE. Jaw cysts - filling or no filling after enucleation? A review. J Craniomaxillofac Surg, 2012, 40(6):485-493. https://doi.org/10.1016/j.jcms.2011.07. 023 PMID: 21890372

[3] Ihan Hren N, Miljavec M. Spontaneous bone healing of the large bone defects in the mandible. Int J Oral Maxillofac Surg, 2008, 37(12):1111-1116. https://doi.org/10.1016/j.ijom.2008. 07.008 PMID: 18760900

[4] Guillerminet V, Keller P, Chatelain B, Denis F. Le volet osseux réalisé à la micro-scie et repositionné in situ : une technique alternative à la decortication [Bony lid using a micro-saw and repositioned in situ: an alternative to decortication]. Med Buccale Chir Buccale, 2015, 21(4):243-247. https://doi.org/ $10.1051 / \mathrm{mbcb} / 2015039$

[5] Gruber R. Mechanism of bone development, remodeling and loss. In: Watzek G (ed). Implants in qualitatively compromised bone. Quintessence Publishing Co., Ltd., United Kingdom, 2004, 9-28.

[6] Anitua E. Molecular and cellular fundamentals of tissue repair: the legacy of evolution. In: Anitua E. Extraction socket treatment a biological approach. Team Work Media España, Vitoria, Spain, 2015, 17-40.

[7] Ogunlewe MO, Akinwande JA, Ladeinde AL, Adeyemo WL. Spontaneous regeneration of whole mandible after total mandibulectomy in a sickle cell patient. J Oral Maxillofac Surg, 2006, 64(6):981-984. https://doi.org/10.1016/j.joms.2006.02. 008 PMID: 16713818

[8] Rodeo SA, Delos D, Weber A, Ju X, Cunningham ME, Fortier L, Maher S. What's new in orthopaedic research? J Bone Joint Surg Am, 2010, 92(14):2491-2501. https://doi.org/10.2106/ JBJS.J.01174 PMID: 20962201

[9] Ratiu C, Brocks M, Costea T, Moldovan L, Cavalu S. PRGFmodified collagen membranes for guided bone regeneration: spectroscopic, microscopic and nano-mechanical investigations. Appl Sci, 2019, 9(5):1035. https://doi.org/10.3390/app9051035

[10] Cieslik-Bielecka A, Bielecki T, Gazdzik TS, Cieslik T, Szczepanski T. Improved treatment of mandibular odontogenic cysts with platelet-rich gel. Oral Surg Oral Med Oral Pathol Oral Radiol Endod, 2008, 105(4):423-429. https://doi.org/ 10.1016/j.tripleo.2007.07.039 PMID: 18206407

[11] Jacobson M, Fufa D, Abreu EL, Kevy S, Murray MM. Platelets, but not erythrocytes, significantly affect cytokine release and scaffold contraction in a provisional scaffold model. Wound Repair Regen, 2008, 16(3):370-378. https://doi.org/10.1111/ j.1524-475X.2008.00376.x PMID: 18471255 PMCID: PMC 3580948

[12] Rodriguez IA, Growney Kalaf EA, Bowlin GL, Sell SA. Plateletrich plasma in bone regeneration: engineering the delivery 
for improved clinical efficacy. BioMed Res Int, 2014, 2014: 392398. https://doi.org/10.1155/2014/392398 PMID: 25050347 PMCID: PMC4094865

[13] Pradel W, Eckelt U, Lauer G. Bone regeneration after enucleation of mandibular cysts: comparing autogenous grafts from tissueengineered bone and iliac bone. Oral Surg Oral Med Oral Pathol Oral Radiol Endod, 2006, 101(3):285-290. https://doi. org/10.1016/j.tripleo.2005.06.001 PMID: 16504859

[14] Bodner L. Effect of decalcified freeze-dried bone allograft on the healing of the jaw defects after cyst enucleation. J Oral Maxillofac Surg, 1996, 54(11):1282-1286. https://doi.org/10. 1016/s0278-2391(96)90482-6 PMID: 8941177

[15] Bodner L. Osseous regeneration in the jaws using demineralized allogenic bone implants. J Craniomaxillofac Surg, 1998, 26(2):116-120. https://doi.org/10.1016/S1010-5182(98) 80051-6 PMID: 9617677

[16] Jensen SS, Broggini N, Hjørting-Hansen E, Schenk R, Buser D. Bone healing and graft resorption of autograft, anorganic bovine bone and $\beta$-tricalcium phosphate. A histologic and histomorphometric study in the mandibles of minipigs. Clin Oral Implants Res, 2006, 17(3):237-243. https://doi.org/10.1111/ j.1600-0501.2005.01257.x PMID: 16672017

[17] Artzi Z, Weinreb M, Givol N, Rohrer MD, Nemcovsky CE, Prasad HS, Tal H. Biomaterial resorption rate and healing site morphology of inorganic bovine bone and beta-tricalcium phosphate in the canine: a 24-month longitudinal histologic study and morphometric analysis. Int J Oral Maxillofac Implants, 2004, 19(3):357-368. PMID: 15214219

[18] Jensen SS, Bornstein MM, Dard M, Bosshardt DD, Buser D. Comparative study of biphasic calcium phosphates with different HA/TCP ratios in mandibular bone defects. A longterm histomorphometric study in minipigs. J Biomed Mater Res B Appl Biomater, 2009, 90(1):171-181. https://doi.org/ 10.1002/jbm.b.31271 PMID: 19085941

[19] Thorwarth M, Schultze-Mosgau S, Kessler P, Wiltfang J, Schlegel KA. Bone regeneration in osseous defects using a resorbable nanoparticular hydroxyapatite. J Oral Maxillofac Surg, 2005, 63(11):1626-1633. https://doi.org/10.1016/j.joms. 2005.06.010 PMID: 16243180

[20] Mooren RECM, Dankers ACA, Merkx MAW, Bronkhorst EM, Jansen JA, Stoelinga PJW. The effect of platelet-rich plasma on early and late bone healing using a mixture of particulate autogenous cancellous bone and Bio-Oss: an experimental study in goats. Int J Oral Maxillofac Surg, 2010, 39(4):371-378. https://doi.org/10.1016/j.ijom.2009.12.019 PMID: 20129756

[21] Joo MV, Chung SJ, Shin SH, Chung YG. The effect of autologous platelet rich plasma on bone regeneration by autologous mesenchymal stem cells loaded onto allogeneic cancellous bone granules. Cell Tissues Organs, 2017, 203(6): 327-338. https://doi.org/10.1159/000454915 PMID: 28118635

[22] Killey HC, Kay LW, Seward GR. Benign cystic lesions of the jaws: their diagnosis and treatment. $3^{\text {rd }}$ edition, Churchill Livingstone, Edinburgh, Medical Division of Longman, Inc. New York, 1977, 123-152. https://doi.org/10.1002/hed.2890 010415

[23] Anitua E, Prado R, Troya M, Zalduendo M, de la Fuente M, Pino A, Muruzabal F, Orive $G$. Implementation of a more physiological plasma rich in growth factor (PRGF) protocol: anticoagulant removal and reduction in activator concentration. Platelets, 2016, 27(5):459-466. https://doi.org/10.3109/095 37104.2016.1143921 PMID: 26940906

[24] Anitua EA. Procedure for obtaining PRGF. In: Anitua EA. A biological approach to implantology. Team Work Media España, Vitoria, Spain, 2015, 89-105.

[25] Anitua E, Sánchez M, Orive G, Andía I. The potential impact of the preparation rich in growth factors (PRGF) in different medical fields. Biomaterials, 2007, 28(31):4551-4560. htpps:// doi.org/10.1016/j.biomaterials.2007.06.037 PMID: 17659771

[26] Vercellotti T. Clinical characteristics and surgical protocols. In: Vercellotti T. Essentials in piezosurgery: clinical advantages in dentistry. Quintessence Publishing Co., Ltd., Milano, Italy, 2009, 21-27.

[27] Yaman Z, Suer BT. Clinical comparison of ultrasonic surgery and conventional surgical techniques for enucleating jaw cyst. Int J Oral Maxillofac Surg, 2013, 42(11):1462-1468. https://doi.org/10.1016/j.ijom.2013.05.003 PMID: 23769149

[28] Kocyigit ID, Athil F, Alp YE, Tekin U, Tuz HH. Piezosurgery versus conventional surgery in radicular cyst enucleation. J Craniofac Surg, 2012, 23(6):1805-1808. https://doi.org/ 10.1097/SCS.0b013e318271014c PMID: 23147343

[29] Labanca M, Azzola F, Vinci R, Rodella LF. Piezoelectric surgery: twenty years of use. Br J Oral Maxillofac Surg, 2008, 46(4):265-269. https://doi.org/10.1016/j.bjoms.2007.12.007 PMID: 18342999

[30] Rullo R, Addabbo F, Papaccio G, D'Aquino R, Festa VM. Piezoelectric device vs. conventional rotative instruments in impacted third molar surgery: relationships between surgical difficulty and postoperative pain with histological evaluations. J Craniomaxillofac Surg, 2013, 41(2):e33-e38. https://doi.org/ 10.1016/j.jcms.2012.07.007 PMID: 22890087

[31] Pappalardo S, Guarnieri R. Randomized clinical study comparing piezosurgery and conventional rotatory surgery in mandibular cyst enucleation. J Craniomaxillofac Surg, 2014, 42(5):e80-e85. https://doi.org/10.1016/j.jcms.2013.06. 013 PMID: 23932541

[32] Khoury F, Khoury C. Mandibular bone block grafts: diagnosis, instrumentation, harvesting techniques and surgical procedures. In: Khoury F, Antoun H, Missika P (eds). Bone augmentation in oral implantology. Quintessence Publishing Co., Ltd., United Kingdom, 2007, 1115-212.

[33] Khoury F, Hanser Th, Khoury Ch, Neugebauer J, Terpelle T, Tunkel J, Zöller JE. Greffons osseux mandibulaires : diagnostic, instrumentation, technique de prélèvement et procédés chirurgicaux. In: Khoury F, Hanser Th, Khoury Ch, Neugebauer J, Terpelle T, Tunkel J, Zöller JE. Greffe osseuse en implantologie. Quintessence Publishing Co., Ltd., Paris, France, 2011, 441-450.

[34] Marx RE, Garg AK. Clinical effects of PRP on bone regeneration. In: Marx RE, Garg AK (eds). Dental and craniofacial applications of platelet-rich plasma. Quintessence Publishing Co., Ltd., Illinois, USA, 2005, 14-18.

[35] Anitua E, Orive G, Pla R, Roman P, Serrano V, Andía I. The effects of PRGF on bone regeneration and on titanium implant osseointegration in goats: a histologic and histomorphometric study. J Biomed Mater Res A, 2009, 91(1):158-165. https:// doi.org/10.1002/jbm.a.32217 PMID: 18780372

[36] Borie E, Oliví DG, Orsi IA, Garlet K, Weber B, Beltrán V, Fuentes R. Platelet-rich fibrin application in dentistry: a literature review. Int J Clin Exp Med, 2015, 8(5):7922-7929. PMID: 26221349 PMCID: PMC4509294

[37] Anitua E, Tejero R, Zalduendo MM, Orive G. Plasma rich in growth factors promotes bone tissue regeneration by stimulating proliferation, migration, and autocrine secretion in primary human osteoblasts. J Periodontol, 2013, 84(8): 1180-1190. https://doi.org/10.1902/jop.2012.120292 PMID: 23088531

[38] Drago L, Bortolin M, Vassena C, Taschieri S, Del Fabro M. Antimicrobial activity of pure platelet-rich plasma against microorganisms isolated from oral cavity. BMC Microbiol, 2013, 13:47. https://doi.org/10.1186/1471-2180-13-47 PMID: 23442413 PMCID: PMC3599521

\section{Corresponding authors}

Adina Bianca Boşca, Associate Professor, DMD, PhD, Discipline of Histology, Department of Morphological Sciences, Faculty of Medicine, luliu Haţieganu University of Medicine and Pharmacy, 6 Louis Pasteur Street, 400349 ClujNapoca, Romania; Phone +40740-248 923, e-mail: biancabosca@yahoo.com

loana Adela Raţiu, Lecturer, MD, PhD, Discipline of Nephrology, Department of Medical Disciplines, Faculty of Medicine and Pharmacy, University of Oradea, 101 Decembrie Square, 410073 Oradea, Romania; Phone +40740-234 773, e-mail: ratiu_ioana@yahoo.com 